\title{
Behaviour towards Risk in Structured Portfolio Management
}

\author{
Hachmi Ben Ameur \\ Amiens School of Management \\ 18, place Saint Michel, 80000, Amiens cedex \\ Tél: 33-(0)3-2282-2457Ｅ-mail: Hachmi.BENAMEUR@supco-amiens.fr \\ Jean Luc Prigent \\ Thema,University of Cergy-Pontoise \\ 33, boulevard du port, 95011, Cergy-Pontoise, France \\ E-mail: Jean-Luc.PRIGENT@u-cergy.fr
}

\begin{abstract}
We examine the optimal design of financial structured portfolios (equity or index linked notes) within the rank dependent utility framework. We illustrate how these products can be in accordance to investor's attitude towards risk, whereas, for the standard expected utility case, they do not match investor's preferences. These financial products usually involve derivative instruments which allow investors to benefit from capital protection and minimal participation when markets are bullish.
\end{abstract}

Keywords: Optimal portfolio design, Structured portfolio, Rank dependent utility, Cumulative prospect theory

\section{Introduction}

The Expected Utility theory (EU) introduced by von Neumann and Morgenstern (1947) has been intensively used to model investor behaviour towards risk. The seminal paper of Markowitz (1952) provides for the first time the optimal static portfolio solution in the mean-variance framework, which is linked to quadratic utility functions. In a continuous-time framework, Merton (1971) determines the optimal portfolio for various utility functions. These results have been further extended in various directions, taking account for example of financial market incompleteness, of specific constraints on portfolio weights, of labor income, of random horizon...as in Cox and Huang (1989), Cvitanic and Karatzas (1996), and, with insurance constraints, El Karoui et al. (2005) and Prigent (2006) (see also Campbell and Viceira, 2002; Prigent, 2007, for a survey about such results). However, some well documented paradoxes, such as the Allais's paradox, have proved that standard utility theory does not model actual behaviour towards risk. As shown by Allais (1953), the independence axiom is not often validated empirically from the observed behavior of individuals. As illustrated also by Cohen and Tallon (2000), the expected utility theory implies that utility function must simultaneously formalize the choice among alternatives and models risk aversion. Thus, for example, an investor with a decreasing marginal utility must have necessarily risk aversion. If the independence axiom is not satisfied, an alternative theory to the expected utility (EU) in order to model the individual attitude towards risk, is the Rank Dependent Expected Utility (RDEU).

The RDEU is a generalization of the expected utility model of choice under uncertainty. It solves the Allais paradox and is in accordance with the empirical observation that often individuals purchase simultaneously lottery tickets and insurance contracts. For the first case, they are risk-lover and for the other case, they exhibit risk aversion. This feature can be explained by first assuming that people overweight low-probability events (winning the lottery), and, second, do not want to bear losses. Among theories that take account of probability deformation, the rank-dependent expected utility has been introduced to overweight mainly unlikely extreme outcomes. In this framework, Quiggin (1982) proposes transformations to be applied to the cumulative probability distribution function, rather than to single probabilities. Tversky and Kahneman (1992) introduce the Cumulative Prospect Theory (CPT). This attempt to model behaviour towards risk considers that people analyze possible outcomes with respect to a given initial reference point rather than to the final value (framing effect). Additionally, their attitudes towards risk differ if they benefit from gains (values above the reference point) or if they suffer from losses (values below the reference point). Potential losses are also better taken into account than potential gains. This behaviour corresponds to loss aversion. Moreover, individuals overweight extreme events and underweight the other ones. Since the beginning of the 2000's, several applications of prospect theory to portfolio and asset pricing theories have been developed. Barberis et al. (2001) examine asset prices when investors behave according to the prospect theory, assuming that investors 
evaluate losses and gains in different manners. McManus et al. (2009) deal with time-varying optimal portfolios in the prospective utility framework, when individuals have a myopic loss aversion.

Simultaneously, new financial products, called "structured products", have been proposed to enhance portfolio returns. They are particularly marketed through mutual funds and life insurance funds. These latter ones are the biggest investors on these products. With the aim of offering to their subscribers a predefined performance in any event in addition to the guarantee of initial capital, insurers use these funds to boost the bond market performance which is characterized by its relatively low yields. Indeed, structured products allow investors to take advantage of the risky asset rises, while being exposed only partially to market drops (see Bertrand and Prigent, 2005). The combination of basic assets gives birth to new assets with very specific characteristics whose evaluation appears very complex. During the periods of financial markets decline and strong volatilities, the demand in favour of the structured products in particular those with a protection clause on capital growths sharply. Indeed, the risk aversion plays a crucial role in the investors behavior. Taking account of the investors psychology, of their cognitive biases and emotional reactions, behavioral finance provides a specific framework for the study of these products. Thus several studies have been published on this research topic. For instance, Hens and Riger (2008) prove that the investor will include more complex structured products than standard equities in his portfolio. Driessen and Maenhout (2007) deals with optimal positioning problems, assuming either expected utility or the CPT of Tversky and Kahneman (1992). Pfiffelmann and Roger (2005), and Pfiffelmann (2008) show how some specific structured products such as capital linked notes depend crucially on the given reference level.

In what follows, we analyze more generally how the financial portfolio optimization theory can explain shapes of structured products within rank dependent expected utility. Section 2 provides a brief survey about main concepts of RDEU and in particular CPT. Section 3 summarizes main features of financial structured products. Section 4 develops results about portfolio optimization within RDEU. We examine first basic examples of such products, in particular for the anticipated utility of Quiggin (1982). Second, we recall the results of Prigent (2008) for the static case and the contributions of Jin and Zhou (2008) in the dynamic framework. We examine the corresponding positions in terms of choice of options to include in the portfolio, such as puts or straddles. Such results can be connected to usual practice. Let us note that in particular, the optimal portfolio profile is not necessarily an increasing function of the risky asset used as benchmark (as for the case of expected utility), but can correspond now to a long or short position in a straddle. This implies the non-monotonicity of portfolio payoff.

\section{2- Non expected utility theory}

Alternative theories have been introduced to adjust or modify significantly the EU classical theory. We can mention for example : the "weighted utility theory" of Chew and MacCrimmon (1979) based on a weakened version of the independence axiom; the "prospect theory" of Kahnemann and Tversky $(1979,1992)$; the "non-linear expected utility theory " of Machina (1982); the "anticipated utility theory" of Quiggin (1982); the "dual theory" of Yaari (1987).

\subsection{First extensions of the expected utility.}

The theory introduced by Chew and MacCrimmon (1979) and further developed by Chew (1989) and Fishburn (1983) is one of the first extensions solving the Allais paradox. This theory is based on a transformation of the initial probability.

Chew's approach leads to the following representation of preferences on the lotteries-type $L=\left\{\left(x_{1}, p_{1}\right), \ldots,\left(x_{m}, p_{m}\right)\right\}$ :

$$
u(L)=\sum_{i} u\left(x_{i}\right) \phi\left(p_{i}\right) \quad \text { with } \quad \phi\left(p_{i}\right)=p_{i} /\left[\sum_{i} v\left(x_{i}\right) p_{i}\right],
$$

where $\mathrm{u}$ and $\mathrm{v}$ are two different elementary utility functions.

Also, one of the most important approach is the "prospect theory" introduced by Tversky and Kahneman (1979). This theory represents preferences by means of a function $\phi$ such that the utility of the lottery $L=\left\{\left(x_{1}, p_{1}\right), \ldots,\left(x_{m}, p_{m}\right)\right\}$ is given by:

$$
u(L)=\sum_{i} u\left(x_{i}\right) \phi\left(p_{i}\right)
$$


where $\phi$ is an increasing function defined on $[0,1]$ with value in $[0,1]$ and verifying $\phi(0)=0, \phi(1)=1$ The function $\phi()$, is a transformation of the initial probability and corresponds to a decision weight functional. It allows us to take account of a "certainty effect". For example, if the function $\phi$ is not left-continuous at 1 , then we can have $\phi(p)<p$ in the neighborhood of 1 .

This transformation allows to solve the Allais paradox. Also, from experimental observations, Tversky and Kahneman (1992) show the necessity to distinguish positive results (gains) from negative ones (losses). The subadditivity of $\phi$ may imply the violation of the first-order stochastic dominance, as well as other models with weighted probabilities. To solve this problem, alternative approaches can be proposed.

This behavioral inconsistency is called the "framing effect". It shows that the mental representation of a problem of choice is crucial. Kahneman and Tversky note that observed preferences in the two problems are particulary interesting because they violate not only the theory of expected utility, but in practice, all choice models based on normative theories.

\subsection{Rank Dependent Expected Utility theory.}

The crucial idea of "Rank Dependent Expected Utility" (RDEU) was to overweight only unlikely extreme outcomes, rather than all unlikely events. The distinguishing characteristic of these models is that the transformed probability of an outcome depends on the rank of the outcomes in the induced preference ordering on the set of outcomes. In this context, we introduce representations of preferences that are compatible with first-order stochastic dominance. In what follows, we define the functional of preference representation. For all random variables $\mathrm{X}$ and $\mathrm{Y}$ which represent results or consequences and with values in $[-M, M]$, we have:

$$
X>Y \Leftrightarrow V(X) \geq V(Y), \text { with } V(Z)=\int_{-M}^{M} u(z) d \phi\left(F_{Z}(z)\right),
$$

where the function $u($.$) is continuous and differentiable, strictly increasing and unique up to a non-negative linear$ transformation.

The function $\phi($.$) is continuous and strictly increasing from [0,1]$ into $[0,1]$. The function $F_{z}($.$) denotes the$ cumulative distribution function (cdf) of $Z$. Note that for a discrete lottery $L=\left\{\left(x_{1}, p_{1}\right), \ldots,\left(x_{m}, p_{m}\right)\right\}$ with $x_{1} \leq x_{2} \leq \ldots . x_{n}$, the utility $\mathrm{V}$ is given by:

$$
\begin{aligned}
& V(L)=\sum_{i=1}^{n} u\left(x_{i}\right)\left[\phi\left(\sum_{j=1}^{i} p_{j}\right)-\phi\left(\sum_{j=1}^{i-1} p_{j}\right)\right], \\
& =u\left(x_{1}\right)+\sum_{i=2}^{n}\left(u\left(x_{i}\right)-u\left(x_{i-1}\right)\right)\left[1-\phi\left(\sum_{j=1}^{i} p_{j}\right)\right] .
\end{aligned}
$$

Since the weights $\phi\left(\sum_{j=1}^{i-1} p_{j}\right)$ depend on the ranking of the outcomes $x_{i}$, this preference representation is called "rank dependent expected utility." These weights are determined by first ranking outcomes from the worst to the best then by summing up the utilities weighted by the sequence $\left(\phi\left(\sum_{j=1}^{i} p_{j}\right)-\phi\left(\sum_{j=1}^{i-1} p_{j}\right)\right)_{i}$. Thus, an objective probability is assumed to exist, but individuals transform this given probability distribution by using a transformation of its cdf. This allows the first-order stochastic dominance.

The expected utility criterion is obtained as a special case of the RDEU model. Indeed, for $\quad \phi(p)=p, \forall p \in[0,1]$, the functional associated to preference representation is given by:

$$
V(L)=\sum_{i=1}^{n} u\left(x_{i}\right)\left[\left(\sum_{j=1}^{i} p_{j}\right)-\left(\sum_{j=1}^{i-1} p_{j}\right)\right]=\sum_{i=1}^{n} p_{i} u\left(x_{i}\right)=E U(L) .
$$

If $\phi$ is not equal to identity but $u(x)=x$, then the RDEU is the dual theory of Yaari (1987). 
As mentioned in Tallon (1997), the RDEU has several advantages. Contrary to the EU, the RDEU models can distinguish between the concept of risk aversion and the assumption of decreasing marginal utility of wealth. Thus, the RDEU is compatible with usual empirical observations which show that individuals under- or overestimate probabilities of random events (i.e., are either pessimistic or optimistic). Contrary also to the EU, the RDEU theory makes possible a clear-cut distinction between risk aversion in the « strong sense » of Rothschild and Stiglitz (1970, 1971), and risk aversion in the "weak sense » of Arrow-Pratt. In what follows, we examine two models in the RDEU framework.

\subsubsection{Anticipated utility theory.}

The EU hypothesis is widely used in various disciplines. However, it sometimes fails to explain some counter examples. Quiggin (1982) successfully solves the problem of first-order stochastic dominance by proposing that probability weights of every prospect are derived from the entire original probability distribution. Quiggin (1982) adds the following axiom to the three main properties of the ES theory: the transitivity, the first-order stochastic dominance, and the continuity. Consider a lottery $L=\left\{\left(x_{1}, p_{1}\right), \ldots,\left(x_{m}, p_{m}\right)\right\}$. Then a functional $\mathrm{V}$ which satisfies Quiggin's conditions is given by:

$$
V(L)=\sum_{i=1}^{n} u\left(x_{i}\right)\left[\phi\left(\sum_{j=1}^{i} p_{j}\right)-\phi\left(\sum_{j=1}^{i-1} p_{j}\right)\right]
$$

where $\phi$ is non-decreasing on $[0,1]$ into $[0,1]$, and is concave on $\left[0, \frac{1}{2}\right], \phi\left(p_{i}\right)>p_{i}$ and convex on $\left[\frac{1}{2}, 1\right]$, $\phi\left(p_{i}\right)<p_{i}$ with $\phi\left(\frac{1}{2}\right)=\frac{1}{2}$ and $\phi(1)=1$.

As proposed in Quiggin (1982), the function $\phi$ can be chosen as follows:

$$
\phi(p)=\frac{p^{\gamma}}{\left(p^{\gamma}+(1-p)^{\gamma}\right)^{\frac{1}{\gamma}}},
$$

with, for example, $\gamma=0.6$.

\section{[PLACE Figure 1 HERE]}

Many empirical experiences have proved that individuals consider losses and gains in an asymmetric way. The value function has several typical properties. It is concave in gains and convex in losses. This reflects diminishing marginal sensitivity to increasing gains and losses. The value function is also steeper for losses than for gains, which is referred to as loss aversion. The value of each component is determined by taking the expected utility with respect to distortions of the distribution function which may differ for the positive and the negative parts of the distribution. Also, main empirical experiences show that people tend to think about possible outcomes usually relatively to a certain reference point rather than to the final status, a phenomenon which is called the framing effect. This kind of behavior is modelled by the "Cumulative Prospect Theory". This model can be viewed as a generalization of the standard rank-dependent utility model, for which the same distortion function is used for the whole distribution.

\subsubsection{Cumulative prospect theory.}

The CPT model assumes that losses and gains are evaluated in different ways and with respect to a reference point which may be the investor's current wealth. Tversky and Kahneman (1992) have introduced both specific utility functions for losses and gains and a transformation function of the cumulative distributions to take account of the many violations of the usual assumptions of expected utility theory. The concave utility function is replaced by a loss-averse utility function and probabilities are replaced by decision weights.

There exist two functions, $w^{-}$and $w^{+}$defined on $[0,1]$, and an utility type function $\mathrm{v}$ such that the utility $\mathrm{V}$ on the lottery $L=\left\{\left(x_{1}, p_{1}\right), \ldots,\left(x_{m}, p_{m}\right)\right\} \quad$ with $x_{1}<\ldots x_{m}<0<x_{m+1}<\ldots .<x_{n}$. is defined as follows: define $\phi^{-}$and $\phi^{+}$ by $\phi_{1}^{-}=w^{-}\left(p_{1}\right)$ and $\phi_{n}^{+}=w^{+}\left(p_{n}\right)$ 


$$
\begin{aligned}
& \phi_{i}^{-}=w^{-}\left(\sum_{j=1}^{i} p_{j}\right)-w^{-}\left(\sum_{j=1}^{i-1} p_{j}\right), \forall i \in\{2, \ldots, m\}, \\
& \phi_{i}^{+}=w^{+}\left(\sum_{j=1}^{n} p_{j}\right)-w^{+}\left(\sum_{j=i+1}^{n} p_{j}\right), \forall i \in\{m+1, \ldots, n\},
\end{aligned}
$$

Then, $\mathrm{V}$ is given by: $V(L)=V^{-}(L)+V^{+}(L)$ with

$$
V^{-}(L)=\sum_{i=1}^{m} v\left(x_{i}\right) \phi_{i}^{-} \quad \text { and } \quad V^{+}(L)=\sum_{i=m+1}^{n} v\left(x_{i}\right) \phi_{i}^{+} .
$$

As in Quiggin (1982), both functions $w^{-}$and $w^{+}$can be chosen as follows: $w(p)=\frac{p^{\gamma}}{\left(p^{\gamma}+(1-p)^{\gamma}\right)^{\frac{1}{\gamma}}}$, with, for example, $\gamma^{-}=0,69$ and $\gamma^{+}=0,61$.

[PLACE Figure2 HERE]

This figure shows the essential inputs of the CPT:

- The reference point which may be the investor's current wealth.

- The individuals under- or overestimate probabilities of random events.

- The losses and gains are evaluated in different ways.

- $\quad$ Agents are risk-averse on gains and risk-taker on losses.

3. Structured Portfolio Management

3.1. Description of structured products.

Structured products make reference to a combination of one or more classical financial instruments (stocks, bonds, indices and derivatives). These products have attractive characteristics for investors such as the protection of initial capital and an enhanced participation to the market performance. During the periods of financial market decline and strong volatilities, the demand for structured products (in particular those with protection clause on capital) rises sharply. Indeed, the risk aversion plays a crucial role in the investor's behaviour. Options strategy evaluation and structured products have been intensively studied since the seminal Black and Scholes model. Measuring the adequacy of these financial instruments to actual investor's behaviour is a new challenge.

\subsection{Empirical evidence.}

Several papers have dealt with optimal portfolios within the rank dependent expected utility framework, but few papers have introduced options to examine the optimal portfolio profile. Liu and Pan (2003) add non-redundant options to examine the allocation problem in the dynamic framework. They use the dynamic programming approach in continuous-time. Hens and Riger (2008) are interested in measuring the performance improvement when portfolio contains structured products. They show that the final payments are more efficient when these products are used. Afterward, with the aim of determining which type of investor may be interested by the introduction of structured products in his portfolio, these authors begin by considering the maximization of the expectation of the standard utility functions that are increasing and concave functions such as CARA, CRRA and quadratic. They assert that a rational investor always searches for a structure of portfolio which offers a strictly convex payment according to the risky part of the portfolio. This is not the case for all the structured products. However, by maximizing the value function derived from the CPT of Kahneman and Tversky (1992), by choosing the reference point as being the initial value of the risky asset and by considering a deformation of the actual probability, they show that the investor will search to compose his portfolio with more complex structured products.

Driessen and Maenhout (2007) empirically study the optimization of a portfolio containing a riskless asset, a risky asset and an OTM put options or ATM straddles. They used data on S\&P 500 index options. They compare mainly two cases: the optimization of the expected utility and of the not-expected utility (CPT of Tversky and Kahneman, 1992; and anticipated utility Quiggin, 1986). They show that a rational investor with CRRA utility takes always short positions on the put and on the straddle. On the other hand, with not expected utilities and by choosing zero as reference point, the investor with highly distorted probability assessments takes long positions on the put option for the two cases (cumulative prospect theory and anticipated utility) and on the straddles for the anticipated utility case. They also find the same positions with the anticipated utility. However, note that their optimization process is based on a procedure like back-testing (they optimize the portfolio dynamically using directly the past data of the risky asset). This optimization on one observed trajectory is not adequate from the theoretical point of view: really it is not the law of the value of the portfolio that is used (who can be estimated on past data) but a realization of this one ("a 
path"). The modification with Quiggin model of the actual laws of probability is thus "diverted" within the framework of their approach. They show that only the investors who deform strongly the probability will take long positions on put and straddle. In this paper, we choose a particular strategy and we observe the sensibility of the quantities invested in each asset.

The reference point plays a crucial role to determine the optimal portfolio structure. Several studies have looked at this particular point: Roger (2008) poses the problem of choice of the reference point. This threshold is not known at date 0 because it is linked to the final value of the risky asset. He shows that, by choosing as a reference the initial value of the underlying asset for cumulative prospect theory, it is never optimal to buy structured products. Therefore, the parameter values of the cumulative prospect theory have to be carefully selected because they can lead to extreme solutions. Pfiffelmann (2008) considers the example of a particular asset: Lottery-linked deposit accounts. She shows that the usual expected utility theory cannot explain the fact that rational investors can be attracted by this kind of product. On the other hand, with the model of the cumulative prospect theory, it is possible to explain the attraction of investors to these funds. In solving the maximization program of the function value associated with these products by the Lagrange method, she determines in particular the structured product price when the investor's reference point is the riskless rate (Note 1). This paper suggests also that it is necessary to adapt the approach of Tversky to model the choice of the structured products.

\section{Optimal positioning of structured funds}

This section extends the results in Leland (1980), Brennan and Solanki (1981), Carr and Madan (2001) and Prigent (2007) to RDEU framework. Suppose that the investor maximizes an expectation of his utility U with possible modification of probabilities (Note 2). He is a price taker (for example, his benchmark S is the SP\&500 and his investment is too weak to modify the index value). Theoretical" but indicates the shape of the optimal payoff that can be further approximated by investing on traded assets.

We consider first the framework of "buy and hold" strategies are chosen at initial time and further not modified. We examine a particular portfolio with three assets: the riskless asset $\mathrm{B}$, the risky asset $\mathrm{S}$ and a put option. We suppose that the risky asset $\mathrm{S}$ follows a geometric Brownian motion. The put is evaluated with the Black-Scholes model.

Suppose that the interest rate $r$ is constant and the stock price has a Lognormal distribution given by:

$$
S_{T}=S_{0} \exp [d T+\sigma \sqrt{T} X\rfloor
$$

where the distribution of $\mathrm{X}$ is the standard Gaussian $N(0,1)$. For example, in a continuous-time framework,

consider a geometric Brownian motion $\left(S_{t}\right)_{t}$ given by:

with $\mathrm{W}$ denotes the standard Brownian motion.

$$
S_{t}=S_{0} \exp \left[\left(\mu-1 / 2 \sigma^{2}\right) t+\sigma W_{t}\right]
$$

Portfolio value with budget constraint at maturity $\mathrm{T}$ is given by:

$$
V_{T}=\alpha B_{T}+\beta S_{T}+\frac{V_{0}-\alpha B_{0}-\beta S_{0}}{P_{0}(K)}\left(K-S_{T}\right)^{+} .
$$

We consider the following parameters values:

$$
B_{0}=1, S_{0}=100, V_{0}=1000, r=2 \% .
$$

We examine two cases: the standard expected utility case and the anticipated utility case with the Quiggin model. For the anticipated utility case, we maximize the expected utility with deformation of the objective probability. The study of the optimal portfolio profile is a quite interesting test for the RDEU models. We analyze the quantitative implications of a theoretical model for different parameter values.

We consider the CARA utility function: For the quadratic and CRRA utility functions, see Ben Ameur (2009) (Note $3)$.

$$
U(x)=\frac{\exp (-a x)}{-a}, a>0
$$

Case 1: maximization of expected utility CARA.

We solve the following optimization problem:

[PLACE Table 1 HERE]

$$
\begin{aligned}
& \operatorname{Max} E_{P}\left[U\left(V_{T}\right)\right] . \\
& \alpha, \beta
\end{aligned}
$$


Simulations show that the composition of the optimal portfolio depends clearly of the investor risk aversion and the risky asset volatility: the higher these parameters, the smaller the amounts invested in risky assets. The following figure illustrate the sensitivities of portfolio payoff to the volatility $\sigma$ and to the risk aversion $\phi$.

\section{[PLACE Figure 3 HERE]}

These graphs show that the maximum of the utility function depends on the risk aversion a and confirm results observed in previous table. Indeed, the higher the risk aversion, the smaller the value of $\beta$ at which the maximum is achieved.

\section{Case 2: Maximization of the anticipated utility CARA}

In this subsection, we examine the optimal portfolio profile of three assets: a riskless asset $\mathrm{B}$, a risky asset $\mathrm{S}$, and a put option. We examine the case of CARA utility function with transformation of the objective probabilities within the Quiggin model. Tables below show that the quantities of risky assets which compose the portfolio are sensitive to market parameters and to the risk aversion of the investor. Indeed, higher volatility and higher risk aversion imply to reduce amounts invested on risky asset.

[PLACE Table 2 HERE]

The following graphs allow us to compare the final portfolio payments and functions of the expected utility within the specific context of anticipated utility functions as in Quiggin (1982). We observe that, with the distortion of probabilities, the investor will always reduce the quantities of risky asset in his portfolio. This allows to get more "conservative" payoff functions.

\section{[PLACE Figure 4 HERE]}

\section{[PLACE Figure 5 HERE]}

These graphs of the expected utility functions confirm the observations that we have made from previous tables and payment functions.

Ben Ameur and Prigent (2010) examine the static framework where the value of the portfolio is assumed to be a function of a given financial benchmark. In particular, they study situations where the actual probability is modified according to the risky asset value. This attitude corresponds to an investor whose portfolio value is a function of only the terminal value of the risky asset. The case where the investor searches for additional guarantees is also investigated. They assume that three basic financial assets are available on the market: the cash corresponding to a discount factor, the bond $\mathrm{B}$ and the stock $\mathrm{S}$ (a financial index for instance). They suppose that the investor determines an optimal payoff $\mathrm{h}$ which is a function defined on the asset values $\left(N_{T}, B_{T}, S_{T}\right)$ at maturity $\mathrm{T}$. If the market is complete, this payoff can be achieved by the investor. The market can be complete for example if all options can be dynamically duplicated by a perfect hedging strategy in continuous-time. It can be also complete in one period setting if all European options are available on the market. Jin and Zhou (2008) deal with the same problem but in the dynamic framework. They demonstrate that the optimal solution can be obtained by splitting the problem into two parts: the first one concerns the losses and the second one concerns the gains. The gains or losses depend directly on the risky asset values.

This solution has interesting properties. On the one hand, the fact that the investor has gains or losses is entirely determined by the fact that the density of the price functional is less or greater than a simple threshold. On the other hand, we note that the optimal portfolio appears as a combination of two types of digital options. However, the part corresponding to the gains is a function that is not constant. Moreover, we recover the traditional profile of the portfolio for the gain part. Additionally, we can introduce guarantee constraints into the optimization program. This allows the modification of the optimal portfolio composition and necessary to have positive quantities of the risky asset.

\section{Conclusion}

Using the theory of rank-dependent utility, the optimal payoff for a given wealth can be determined for a large class models. This kind of result shows that derivatives product have to be introduced into the portfolio to maximize the utility of the investor. The optimal solution depends clearly on the risk aversion of the investor, on his "behavioral" probability transformation and, under insurance constraint, it also depends on the insured proportion at maturity. The optimal portfolio is determined for several forms of utility functions, probability transformations and insurance constraints. In the case without constraint, the concavity/convexity and monotonicity of portfolio profile is determined from the behavioral parameters (degree of risk aversion and behavorial probability transformation) and from the performance of financial markets, for example the Sharpe ratio type. These results are always verified under insurance constraints at maturity. They can be extended to continuous time models, by using for example the 
dynamic completeness. Assuming that the probability transformation corresponds to the expected conditional of the density of the transformed probability, the result would be rather direct and relatively easy to establish. However dynamic probability transformation is not yet a solved problem and the assumptions are not clearly justified. For the static case, the observation is only relevant at the initial time, so that this type of problem does not occur.

\section{References}

Allais, M. (1953). Le comportement de l'homme rationnel devant le risque: critique des postulats et axiomes de l'école américaine, Econometrica, 21, 503-546.

Barberis, N., Huang, M. and T. Santos (2001). Prospect theory and asset prices, Quaterly Journal of Economics, 116, $1-53$.

Bazak, S. (1995). A general equilibrium model of portfolio insurance, Review of Financial Studies, 8, 1059-1090.

Ben Ameur, H. (2009). Portfolio choice: guarantee clauses and attitude toward risk, PhD thesis, University of Cergy-Pontoise.

Ben Ameur, H. and Prigent, J.-L. (2010). Dynamic versus static optimization within rank dependent expected utility, Working Paper, University of Cergy-Pontoise.

Bernoulli, D. (1954). Exposition of a new theory on the measurement of risk, Econometrica, 22, 23-36.

Bertrand, P. and Prigent, J.-L. (2005). Portfolio insurances strategies: OBPI versus CPPI, Finance, 26, 5-32.

Black, F. and Jones, R. (1987). Simplifying portfolio insurance, Journal of Portfolio Management, 48-51.

Breeden, D. and Litzenberger, R. (1978). Prices of state contingent claims implicit in options prices, Journal of Business, 51, 621-651.

Brennan, M.J. and Solanki, R. (1981). Optimal portfolio insurance, Journal of Financial and Quantitative Analysis, $16,3,279-300$.

Campbell, J. Y. and Viceira, L.M. (2002). Strategic Asset Allocation: Portfolio Choice for Long-Term Investors, Clarendon Lecture in Economics, Oxford University Press, New York.

Carr, P. and Madan, D. (2001). Optimal Positioning in Derivative Securities, Quantitative Finance, 1, 19-37.

Chew, S. (1989). Axiomatic utility theories with betweenness property, Annals of Operations Research, 19, 273-298.

Chew, S.-H. and MacCrimmon, K.R. (1979). Alpha-nu choice theory: a generalization of expected utility theory, Working Paper No. 669, University of British Columbia, Vancouver.

Cohen, M. and Tallon, J.-M. (2000). Décision dans le risque et l'incertain : l'apport des modèles non-additifs, Revue d'Economie Politique, 110.

Cox, J. and Huang, C.-F. (1989). Optimal consumption and portfolio policies when assets prices follow a diffusion process, Journal of Economic Theory, 49, 33-83.

Cvitanic, J. and Karatzas, I. (1996). Contingent claim valuation and hedging with constrained portfolio. IMA volume in Math, Davis M., Duffie D., Fleming, W. and S.E. Shreve, eds, 65, 13-33.

De Giorgi, E., Hensz, T. and Mayerx, J. (2008). A behavioral foundation of reward-risk portfolio selection and the asset allocation puzzle, Working paper, University of Zurich.

De Palma, A., Picard, N., and Prigent, J.-L. (2007). Eliciting utility for (non)expected utility preferences using invariance transformations. Proceedings of the XIII International Conference on the Foundations and Applications of Utility, Risk and Decision Theory, FUR XIII (Barcelone, July 2008).

De Palma, A., and Prigent, J.-L. (2009). Standardized versus customized portfolio: a compensating variation approach, Annals of Operations Research, 165, 161-185.

Driessen, J. and Maenhout, P. (2007). An empirical portfolio perspective on option pricing anomalies, Review of Finance, 11, 561-603.

Eeckhoudt, L. (1997). La théorie duale des choix risqués et la diversification: quelques réflexions, Finance, 18, 77-84.

Ekeland, I. and Turnbull, T. (1983). Infinite-Dimensional Optimization and Convexity. Chicago Lectures in Mathematics, the University of Chicago Press. 
El Karoui, N., Jeanblanc, M. and Lacoste, V. (2005). Optimal portfolio management with American capital guarantee, J. Economics, Dynamics and Control, 29, 449-468.

Gollier, C. (2001). The Economics of Risk and Time, The MIT Press, Cambridge, MA.

Grossman, S. and Zhou, J. (1996). Equilibrium analysis of portfolio insurance, Journal of Finance, 51, 1379-1403.

Hens, T. and Riger, M. O. (2008). The dark side of the moon: structured products from the customer's perspective. Working paper 459, ISB, University of Zurich.

Hong, H. and Stein, J. (1999). An unified theory of underreaction, momentum trading and overreaction in asset markets, Journal of Finance, 54, 2143-2184.

Jin, H. and Zhou, X.Y. (2008). Behavorial portfolio selection in continuous time, Mathematical Finance, 18, $385-426$.

Kahneman, D. and Tversky, A. (1979). Prospect theory: an analysis of decision under risk, Econometrica, 47, 263-291.

Karatzas, I., Lehoczky, J., Sethi, S.P. and Shreve, S.E. (1986). Explicit solution of a general consumption/investment problem, Mathematics of Operations Research, 11, 261-294.

Laffont, J-J. (1993). The Economics of Uncertainty and Information, Cambridge, The MIT Press, MA.

Machina, M. (1982). Choice under uncertainty: problems solved and unsolved, Journal of Economic Perspectives, 1, 281-96.

Markowitz, H. (1952). Portfolio Selection, The Journal of Finance, Vol. 7, N. 1, pp. 77-91.

Merton, R.C. (1971). Optimum consumption and portfolio rules in a continuous time model, Journal of Economic Theory, 3, 373-413.

Von Neumann J. and Morgenstern O. (1947). Theory of Games and Economic Behavior, Princeton, Princeton University Press.

Pfiffelmann, M. (2008). Why expected utility theory cannot explain LLDA? The ICFA Journal of Behavioral Finance,2.

Pfiffelmann, M., and Roger, P. (2005). Les comptes d'épargne associés à des loteries: approche comportementale et études de cas, Banque et Marchés, 78, 16-23.

Prigent, J.-L. (2006). Generalized option based portfolio insurance. Working paper ThEMA, Cergy, France.

Prigent, J.-L. (2007). Portfolio Optimization and Performance Analysis. Boca Raton (Florida). Chapman \& Hall.

Prigent, J.-L. (2008). Portfolio optimization and rank dependent expected utility. Working paper ThEMA, Cergy, France.

Quiggin, J. (1982). A theory of anticipated utility, Journal of Economic Behavior and Organization, 8, 641-645.

Roger, P. (2008). Capital protected notes for loss averse investors: how should they be advertised? Working paper, LARGE, University of Strasbourg.

Rothschild, M. and Stiglitz, J.E. (1970). Increasing risk: I. A definition, Journal of Economic Theory, 2, 225-243.

Rothschild, M. and Stiglitz, J.E. (1971). Increasing risk: II. Its economic consequences, Journal of Economic Theory, 3, 66-84.

Tversky, A. and Kahneman, D. (1992). Advances in prospect theory: cumulative representation of uncertainty, Journal of Risk and Uncertainty, 5, 297-323.

Wakker, P. and Deneffe, D. (1996). Eliciting von Neumann-Morgenstern utilities when probabilities are distorted or unknown, Management Science, 42, 1131-1150.

Yaari, M.E. (1987). The dual theory of choice under risk, Econometrica, 55, 95-115.

\section{Notes}

Note 1. See also Pfiffelmann and Roger (2005)

Note 2. This framework is quite general: it includes for example the weighted utility introduced in Chew (1989), the rank-dependent utility (see Segal, 1989) or the cumulative prospect theory of Kahneman and Tversky (1992).

Note 3. For the quadratic and CRRA utility functions, see Ben Ameur (2009). 
Table 1. Values of the CARA optimal quantities for $\mathrm{K}=100$

The parameter $\mathrm{m}$ denotes a Sharpe type ratio equal to $\frac{\mu-r}{\sigma^{2}}$

For $\mathrm{a}=10^{-3}$

\begin{tabular}{|c|c|c|c|c|c|c|c|}
\hline strike & A & $\mathrm{Mu}$ & Sigma & $\mathrm{m}$ & Alpha & beta & Teta \\
\hline 100 & 0.001 & 0.04 & 0.2 & 0.5 & 76735 & -512 & $(-3537.39004)$ \\
\hline 100 & 0.001 & 0.04 & 0.3 & 0.2222 & 22703 & -144 & $(-673.618461)$ \\
\hline 100 & 0.001 & 0.07 & 0.2 & 1.25 & 4194303 & 0 & $(-604579.105)$ \\
\hline 100 & 0.001 & 0.07 & 0.3 & 0.5556 & 95935 & -672 & $(-2558.23744)$ \\
\hline 100 & 0.001 & 0.1 & 0.2 & 2 & 1048575 & 0 & $(-151036.535)$ \\
\hline 100 & 0.001 & 0.1 & 0.3 & 0.8889 & 4194303 & 0 & $(-386784,378)$ \\
\hline
\end{tabular}

For $\mathrm{a}=10^{-2}$

\begin{tabular}{|r|l|l|l|l|r|r|r|}
\hline strike & A & Mu & Sigma & m & alpha & beta & Teta \\
\hline 100 & 0.01 & 0.04 & 0.2 & 0.05 & 9951 & -64 & $(-367.796292)$ \\
\hline 100 & 0.01 & 0.04 & 0.3 & 0.0222 & 3144 & -14 & $(-68.6255148)$ \\
\hline 100 & 0.01 & 0.07 & 0.2 & 0.125 & 262143 & 0 & $(-37650,8927)$ \\
\hline 100 & 0.01 & 0.07 & 0.3 & 0.0556 & 10263 & -68 & $(-227,18366)$ \\
\hline 100 & 0.01 & 0.1 & 0.2 & 0.2 & 131071 & 0 & $(-18753.2856)$ \\
\hline 100 & 0.01 & 0.1 & 0.3 & 0.0889 & 524287 & 0 & $(-48267.2578)$ \\
\hline
\end{tabular}

Table 2. Optimal quantities (CARA, AU, 3 assets, $\mathrm{K}=100$ )

For $\mathrm{a}=10^{-3}$

\begin{tabular}{|r|l|l|l|l|r|r|r|}
\hline strike & a & Mu & Sigma & M & Alpha & beta & teta \\
\hline 100 & 0.001 & 0.04 & 0.2 & 0.5 & 72191 & -512 & $(-2882.24841)$ \\
\hline 100 & 0.001 & 0.04 & 0.3 & 0.2222 & 15111 & -88 & $(-489.879179)$ \\
\hline 100 & 0.001 & 0.07 & 0.2 & 1.25 & 4194303 & 0 & $(-604579.105)$ \\
\hline 100 & 0.001 & 0.07 & 0.3 & 0.5556 & 86591 & -608 & $(-2286.68701)$ \\
\hline 100 & 0.001 & 0.1 & 0.2 & & 2 & 1048575 & 0 \\
\hline 100 & 0.001 & 0.1 & 0.3 & 0.8889 & 4194303 & $(-151036.535)$ \\
\hline
\end{tabular}

For $\mathrm{a}=10^{-2}$

\begin{tabular}{|r|l|l|l|l|r|l|l|}
\hline strike & a & Mu & sigma & M & Alpha & beta & teta \\
\hline 100 & 0.01 & 0.04 & 0.2 & 0.05 & 8215 & -52 & $(-290.51726)$ \\
\hline 100 & 0.01 & 0.04 & 0.3 & 0.0222 & 2340 & -9 & $(-40.5849819)$ \\
\hline 100 & 0.01 & 0.07 & 0.2 & 0.125 & 262143 & 0 & $(-37650,8927)$ \\
\hline 100 & 0.01 & 0.07 & 0.3 & 0.0556 & 8975 & -56 & $(-219.066664)$ \\
\hline 100 & 0.01 & 0.1 & 0.2 & 0.2 & 131071 & 0 & $(-18753.2856)$ \\
\hline 100 & 0.01 & 0.1 & 0.3 & 0.0889 & 524287 & 0 & $(-48267.2578)$ \\
\hline
\end{tabular}




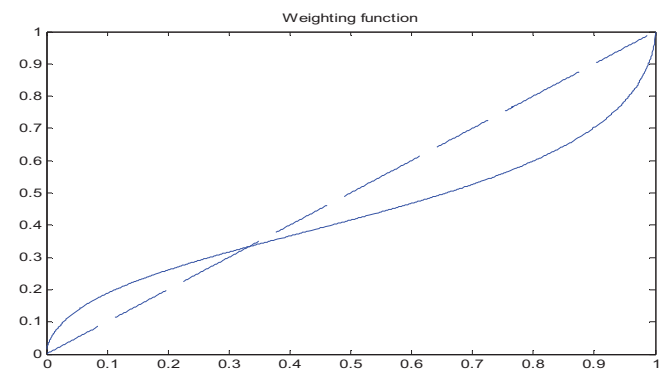

Figure 1. Weighting function

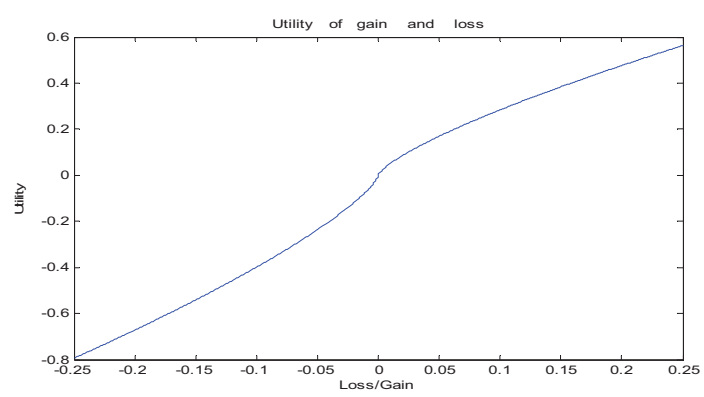

Figure 2. Loss/Gain utility
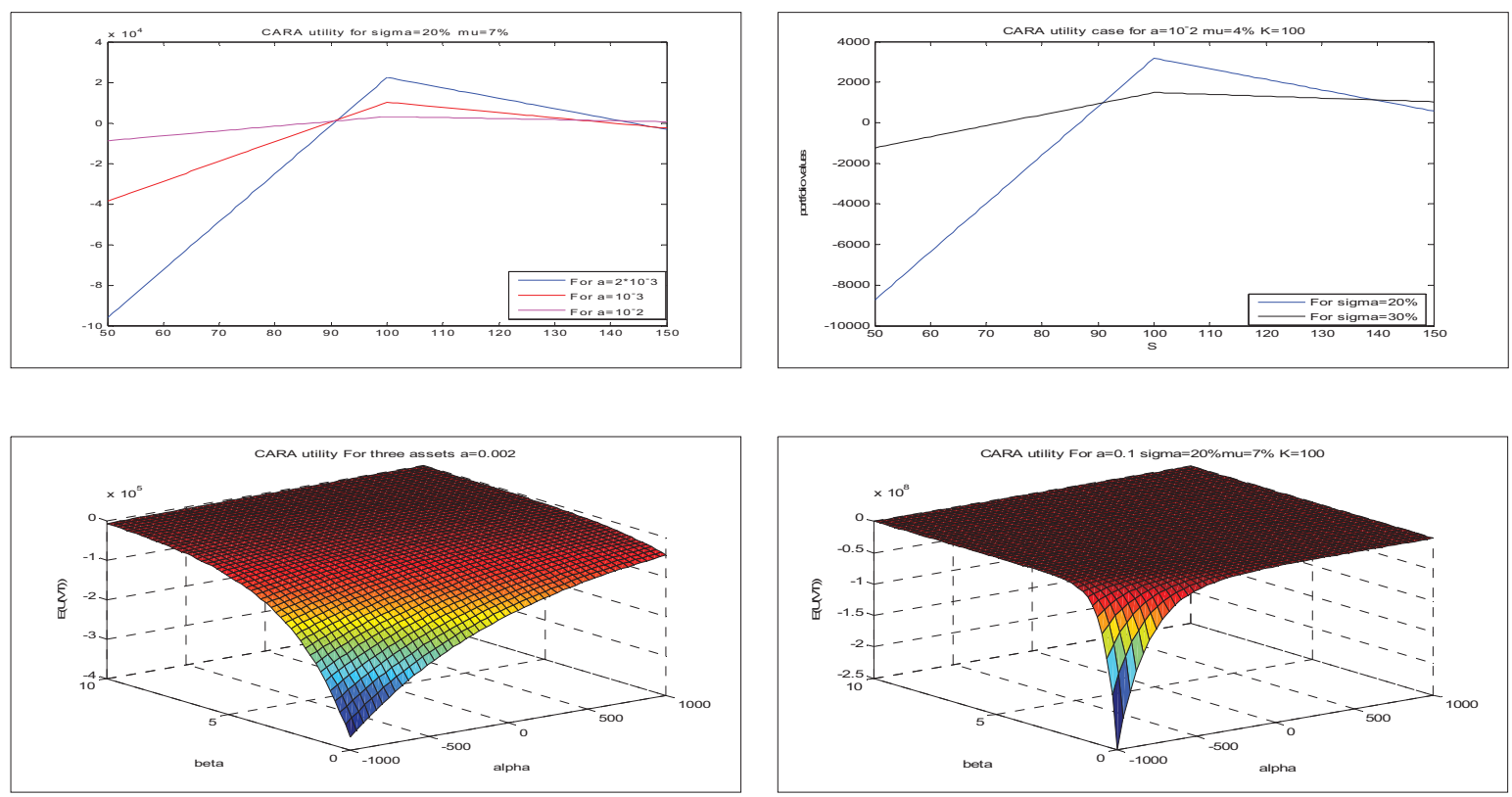

Figure 3. The expected utility CARA for three assets depending on quantities invested on S and B 

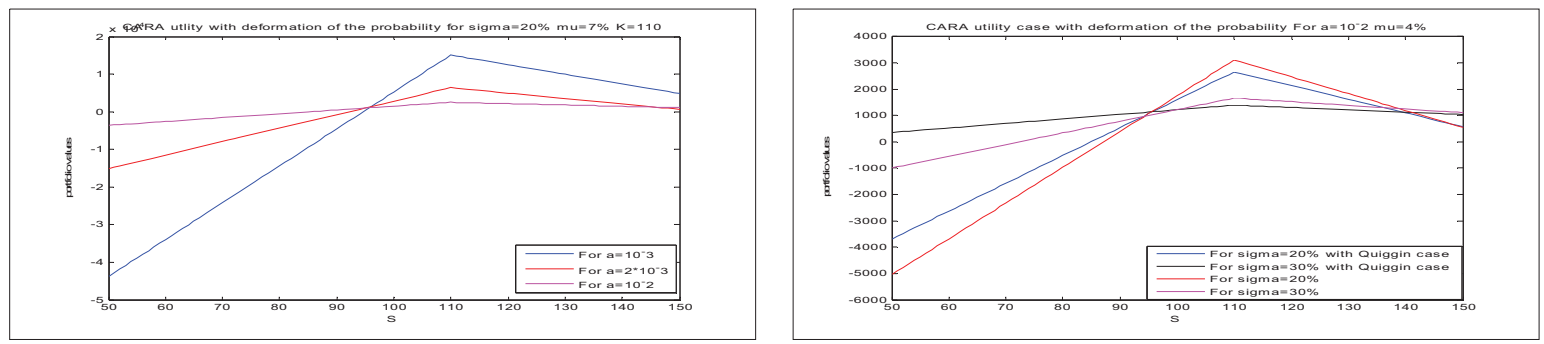

Figure4. Portfolio Payment consisting of three assets with anticipated utility CARA
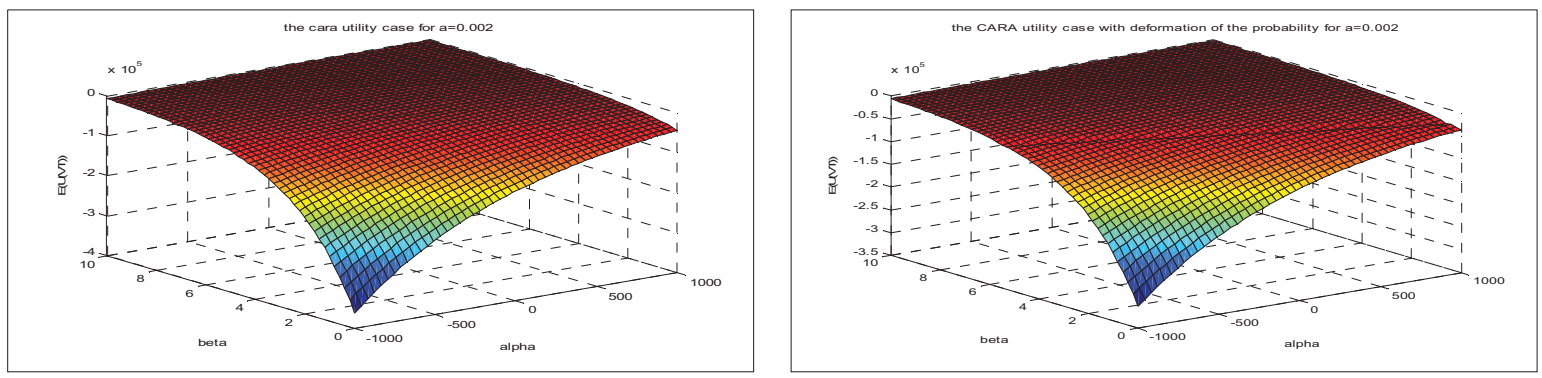

Figure5. The anticipated utility CARA for three asset depending on quantities $\mathrm{S}$ and B invested 